\title{
ANALISIS JENIS PONDASI PADA GEDUNG REKTORAT AKPER SUMBAWA KABUPATEN SUMBAWA
}

Oleh : Badaruddin, Yenni Wulandari dan Mayasari

\section{ABSTRAK}

Akademi Keperawatan (AKPER) Sumbawa merupakan salah satu universitas yang saat ini dalam proses pembangunan dengan perencanaan 3 lantai dan 1 lantai sebagai basement dengan rencana pondasi menggunakan pondasi telapak.Untuk menentukan perencanaan suatu struktur pondasi yang kuat, aman, mudah dikerjakan pada saat pelaksanaan pembangunan struktur, maka penulis menganalisis jenis pondasi telapak pada gedung Rektorat AKPER sehingga mendapatkan pondasi yang efektif dan efisien.

Perhitungan mekanika st ruktur gedung Rektorat AKPER menggunakan Metode Cross dan didapatkan nilai beban ultimit terbesar terdapat pada Portal $2 X$ arah memanjang sebesar $P u=281,5008 \mathrm{kN}$ dengan momen ultimit $M u=5,10369 \mathrm{kNm}$. Sedangkan Portal $1 Y$ arah melintang $P u=163,514 \mathrm{kN}$ dengan momen ultimit $\mathrm{Mu}=0,506 \mathrm{kNm}$. Perhitungan daya dukung tanah menggunakan metode Mayerhorf dan didapatkan hasil daya dukung sebesar qa=288,8 kN/ $\mathrm{m}^{2}$.

Berdasarkan Perhitungan struktur pondasi telapak pada gedung Rektorat AKPER SUmbawa, maka nilai pembebanan dan momen ultimit yang digunakan sebagai dasar perencanaan pondasi meliputi perhitungan pondasi eksisting dan pondasi rencana, dimana diperoleh perbedaan dimensi pondasi telapak Eksisting $2 \times 2$ meter dengan anggaran biaya Rp.4.692.506,93-dan pondasi pinggir 1,7x1,7 meter dengan anggaran biaya Rp.3.419.841,77 sedangkan pondasi rencana dengan dimensi 1,7x1,7 meter maka anggaran biaya Rp.4.109.498,02- dan pondasi pinggir dimensinya 1,5x1,5 dengan anggaran biaya Rp.3.199.436,17Sehingga didapatkan dimensi pondasi yang lebih efektif dan efisien digunakan pada gedung Rektorat AKPER adalah pondasi dengan dimensi 1,7x1,7 untuk pondasi tengah dan dimensi 1,5x1,5 untuk pondasi pinggir.

Kata kunci : struktur, pondasi telapak,perbandingan dimendi pondasi, RAB

\section{PENDAHULUAN}

Pada perencanaan pembangunan gedung bertingkat tinggi harus diperhatikan beberapa aspek penting, seperti lingkungan sosial, ekonomi, serta aspek keamanan, sehingga setiap hambatan yang mungkin terjadi dimasa yang akan datang dapat teratasi dengan baik. Keberadaan pondasi pada konstruksi bangunan sangat penting dan perlu mendapat perhatian lebih, karena merupakan salah satu tahapan penting dalam perencanaan sebuah konstruksi bangunan yang harus mampu menopang konstruksi yang ada diatasnya maupun berat sendiri pondasi tersebut. Banyak dilihat kegagalan konstruksi bangunan 


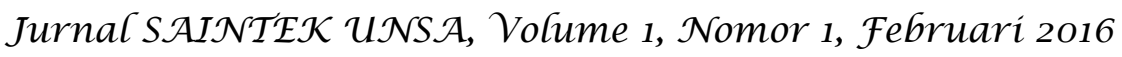

yang disebabkan oleh kurang baiknya perencanaan pondasi pada gedung tersebut.

Selain itu, kondisi tanah juga sangat mempengaruhi kekuatan pondasi. Dengan mengetahui daya dukung tanah, dapat dipilih jenis pondasi yang cocok untuk digunakan. Kondisi lahan tanah yang digunakan untuk pembangunan gedung kampus AKPER merupakan semak belukar dengan kontur yang tidak rata dan kondisi tanah yang bergelombang. Dengan kondisi tanah yang seperti ini bisa diperkirakan pondasi apa yang bisa dijadikan pilihan untuk kontruksi pondasi gedung kampus AKPER Sumbawa Kabupaten Sumbawa .

Pembangunan gedung Kampus Akademi Keperawatan (AKPER) Sumbawa merupakan salah satu dari beberapa gedung yang saat ini dalam proses pembangunan, yang berfungsi sebagai tempat untuk proses belajar mengajar dan menunjang kegiatan lainnya bagi mahasiswa keperawatan. Penelitian ini dilakukan pada kampus AKPER khususnya gedung Rektorat AKPER berlantai tiga dengan struktur bawahnya berupa pondasi tiang pancang dan pondasi telapak.

Mengingat pentingnya perencanaan struktur pondasi pada konstruksi bangunan gedung bertingkat di Kampus AKPER Sumbawa, maka perlu dilakukan suatu kajian khusus untuk analisis jenis pondasi pada gedung Rektorat AKPER Sumbawa . 


\section{METODE PENELITIAN}

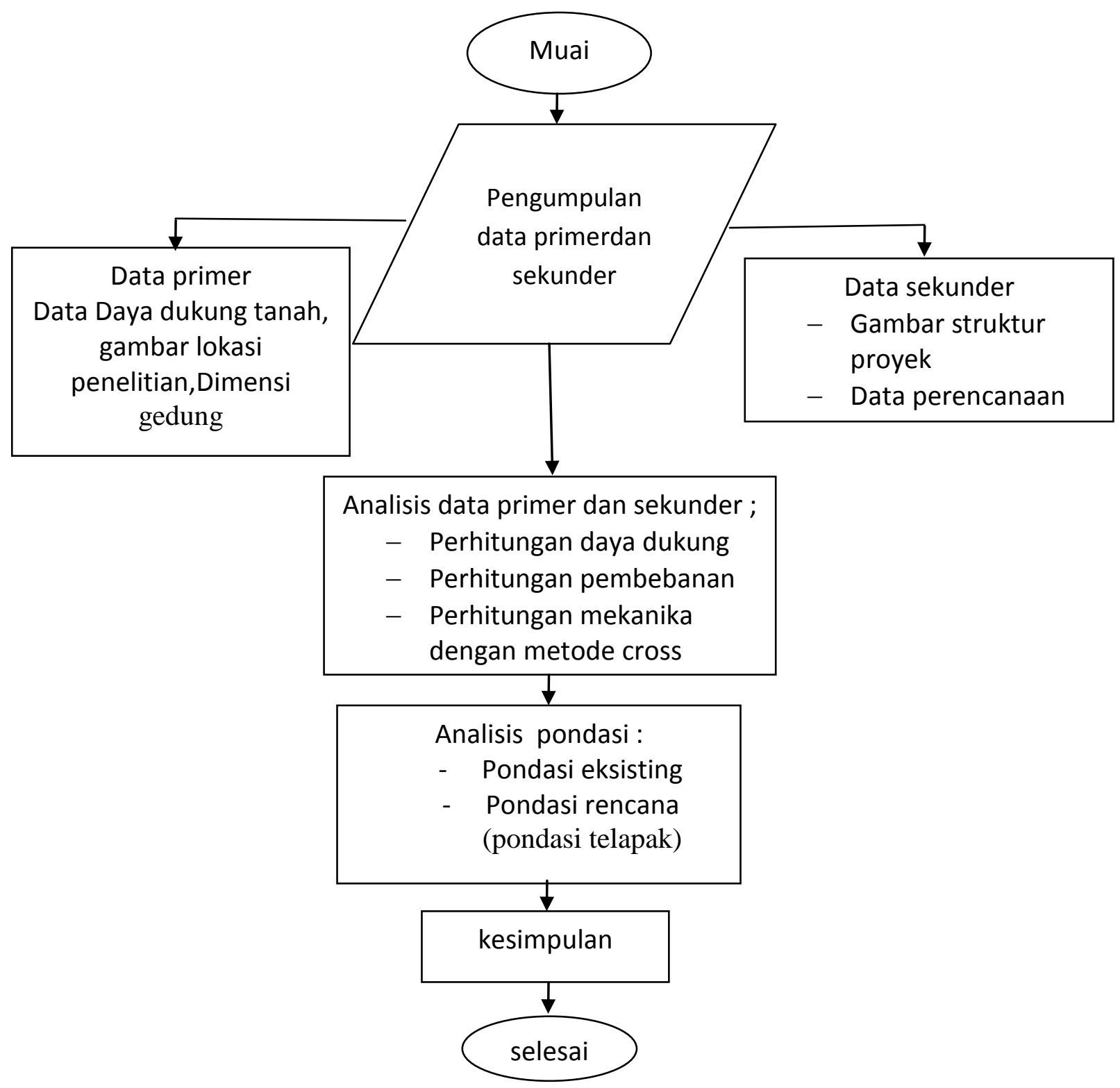

Gambar 1. Bagan alir

Tahapan awal yang dilakukan adalah menggumpulkan data, yang berupa data primer dan data sekunder. Data primer berupa data yang didapat dilapangan berupa data daya dukung tanah yang diperoleh dari uji sondir, gambar lokasi penelitian dan dimensi gedung. Adapun data sekunder adalah data yang diperoleh dari instansi terkait berupa gambar lokasi proyek dan data pembebanan gedung Rektorat AKPER Sumbawa. 


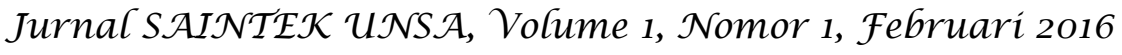

Tahapan selanjutnya adalah tahapan analisis. Hal-hal yang dilakukan dalam menganalisis yaitu :

a) Mengghitung daya dukung tanah dari hasil tes sondir dengan metode mayerhorf.

b) Menghitung pembebanan statika dengan menggunakan Metode Cross dengan tahapan perhitungan sebagai berikut :

1. Menghitung pembebanan dari atap sampai lantai

2. Menghitung beban plat lantai

3. Menghitung momen primer masing-masing portal

4. Perhitungan tabel Cross

5. Membuat bagan momen masing-masing portal

6. Freebody masing-masing portal

7. Gambar bidang MDN

c) Perhitungan pondasi berupa pondasi eksisting dan pondasi rencana. Adapun tahap perhitungannya yaitu :

1. Menghitung dimensi pondasi

2. Menghitung tegangan

3. Menghitung gaya geser satu arah dan dua arah

4. Menghitung tulangan pada pondasi

d) Membuat RAB pondasi .

e) Membuat kesimpulan dan saran.

\section{HASIL DAN PEMBAHASAN}

Berdasarkan data uji sondir didapatkan nilai tahanan konus yang nantinya akan digunakan untuk menghitung daya dukung tanah sehingga dapat disimpulkan pondasi yang cocok digunakan pada gedung Rektorat AKPER Sumbawa. Berikut tabel kedalaman dan perlawanan konus. 


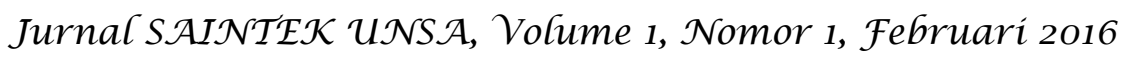

Tabel 4.1. Data Kedalaman dan Perlawanan Konus

\begin{tabular}{|c|c|c|}
\hline \multirow{2}{*}{ kedalaman $\mathrm{h}$} & \multicolumn{2}{|c|}{$\begin{array}{c}\text { Tahanan konus ,qc } \\
\left(\mathrm{kg} / \mathrm{cm}^{2}\right)\end{array}$} \\
\hline$(\mathrm{m})$ & titik S -01 & titik S -02 \\
\hline 1 & 2 & 3 \\
\hline 1.00 & 115 & 85 \\
\hline 1.20 & 85 & 100 \\
\hline 1.40 & 130 & 60 \\
\hline 1.60 & 130 & 60 \\
\hline 1.80 & 240 & 100 \\
\hline 2.00 & 250 & 250 \\
\hline nilai qc rata-rata & 158,333333 & 109,1666667 \\
\hline
\end{tabular}

Sumber : Data Sondir PU Kab. Sumbawa

Perhitungan daya dukung untuk pondasi telapak dan pondasi tiang pancang menggunakan Metode Mayerhorf.

1). Pondasi telapak

Dengan menggunakan persamaan 2.12 didapatkan hasil daya dukung (qa) yaitu sebesar $2,888 \mathrm{~kg} / \mathrm{cm}^{2}$.

2). Pondasi tiang pancang

Dengan menggunakan persamaan (2.20) dan (2.21) didapatkan nilai daya dukung untuk pondasi tiang pancang dapat dilihat pada tabel berikut :

Tabel 4.2. Perhitungan Daya Dukung Ultimit Dan Ijin Pondasi Tiang Berdasarkan Data Sondir (S-1)

\begin{tabular}{|c|c|c|c|c|c|c|}
\hline Kedalaman & PPK (qc) & $\mathbf{A p}$ & $\mathbf{J H L}$ & $\mathbf{K 1 1}$ & Qult & $\mathbf{Q}$ ijin \\
\hline Meter & $\mathbf{k g} / \mathbf{c m}^{\mathbf{2}}$ & $\mathbf{c m}^{\mathbf{2}}$ & $\mathbf{~ k g / \mathbf { c m } ^ { \mathbf { 2 } }}$ & $\mathbf{C m}$ & Ton & Ton \\
\hline $\mathbf{1}$ & $\mathbf{2}$ & $\mathbf{3}$ & $\mathbf{4}$ & $\mathbf{5}$ & $\mathbf{6}$ & $\mathbf{7}$ \\
\hline 0,2 & 0 & 706,5 & 0 & 94,2 & 0 & 0 \\
\hline 0,4 & 25 & 706,5 & 10 & 94,2 & 18,6045 & 6,0759 \\
\hline 0,6 & 65 & 706,5 & 30 & 94,2 & 48,7485 & 15,8727 \\
\hline 0,8 & 115 & 706,5 & 50 & 94,2 & 85,9575 & 28,0245 \\
\hline 1 & 115 & 706,5 & 80 & 94,2 & 88,7835 & 28,5897 \\
\hline 1,2 & 85 & 706,5 & 150 & 94,2 & 74,1825 & 22,8435 \\
\hline 1,4 & 130 & 706,5 & 210 & 94,2 & 111,627 & 34,5714 \\
\hline 1,6 & 130 & 706,5 & 260 & 94,2 & 116,337 & 35,5134 \\
\hline 1,8 & 240 & 706,5 & 280 & 94,2 & 195,936 & 61,7952 \\
\hline 1,9 & 250 & 706,5 & 280 & 94,2 & 203,001 & 64,1502 \\
\hline
\end{tabular}

sumber: hasil perhitungan 
Jurnal SAIJ $\mathcal{N}$ EK UNS $\mathcal{A}$, Volume 1, Nomor 1, Februari 2016

Tabel 4.3. Perhitungan Daya Dukung Ultimit Dan Ijin Pondasi Tiang Berdasarkan Data Sondir (S-2)

\begin{tabular}{|c|c|c|c|c|c|c|}
\hline Kedalaman & PPK (qc) & $\mathbf{A p}$ & $\mathbf{J H L}$ & $\mathbf{K 1 1}$ & Qult & Q ijin \\
\hline Meter & $\mathbf{k g} / \mathbf{c m}^{\mathbf{2}}$ & $\mathbf{c m}^{\mathbf{2}}$ & $\mathbf{k g} / \mathbf{c m}^{\mathbf{2}}$ & $\mathbf{c m}$ & Ton & Ton \\
\hline $\mathbf{1}$ & $\mathbf{2}$ & $\mathbf{3}$ & $\mathbf{4}$ & $\mathbf{5}$ & $\mathbf{6}$ & $\mathbf{7}$ \\
\hline 0,2 & 0 & 706,5 & 0 & 94,2 & 0 & 0 \\
\hline 0,4 & 27 & 706,5 & 10 & 94,2 & 20,0175 & 6,5469 \\
\hline 0,6 & 20 & 706,5 & 80 & 94,2 & 21,666 & 6,2172 \\
\hline 0,8 & 30 & 706,5 & 110 & 94,2 & 31,557 & 9,1374 \\
\hline 1 & 85 & 706,5 & 120 & 94,2 & 71,3565 & 22,2783 \\
\hline 1,2 & 100 & 706,5 & 140 & 94,2 & 83,838 & 26,1876 \\
\hline 1,4 & 60 & 706,5 & 190 & 94,2 & 60,288 & 17,7096 \\
\hline 1,6 & 60 & 706,5 & 230 & 94,2 & 64,056 & 18,4632 \\
\hline 1,8 & 100 & 706,5 & 320 & 94,2 & 100,794 & 29,5788 \\
\hline 2 & 250 & 706,5 & 320 & 94,2 & 206,769 & 64,9038 \\
\hline
\end{tabular}

sumber: hasil perhitungan

Berdasarkan data sondir, dari hasil perhitungan didapatkan bahwa daya dukung ultimite tiang pancang pada kedalaman 1 meter pada titik sondir 1 (S-1) adalah qult=88,78 ton, dan daya dukung ijinnya q ijin= 22,278 ton, untuk titik sondir 2 (S-2) qult=71,536 ton dan q ijin=22,78 ton. Adapun untuk daya dukung ultimite pada kedalaman 2 meter pada titik sondir 1 (S-1) adalah qult=230,001 ton, q ijin=64,15 ton , dan untuk titik sondir 2 (S-2) qult=206,769 ton dan q ijin=64,903 ton .

Secara teoritis dari data sondir dapat diketahui bahwa penggunaan pondasi tiang pancang pada gedung Rektorat AKPER Sumbawa kurang efisien apabila digunakan, karena pada kedalaman 2 meter daya dukungnya sudah sangat besar, sehingga pondasi tiang pancang tidak perlu dijadikan alternatif pondasi pilihan untuk gedung Rektorat AKPER Sumbawa.

\section{Perhitungan struktur}

Berdasarkan hasil perhitungan struktur gedung rektorat AKPER sumbawa dengan menggunakan metode cross ( distribusi momen ) didapatkan momen dan beban terbesar pada masing-masing kolom, dipilih dimensi kolom $40 / 40$ pada portal $2 \mathrm{X}$ untuk pondasi tengah dengan nilai $\mathrm{Pu}=281,5008 \mathrm{kN}$ dan 


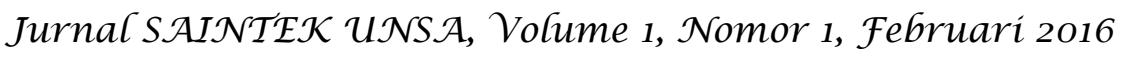

$\mathrm{Mu}=5,1036 \mathrm{kNm}$, dan dimensi kolom 40/40 pada portal 1Y untuk pondasi pinggir dengan nilai $\mathrm{Pu}=163,5137 \mathrm{kN}$ dan $\mathrm{Mu}=0,5055 \mathrm{kNm}$ (laporan perhitungan struktur dengan Metode Cross, terlampir ), yang akan digunakan sebagai beban ultimit dan momen ultimit pada perhitungan analisis pondasi telapak.

Analisis pondasi . Analisis pondasi meliputi pondasi eksisting dan juga pondasi rencana.

1). Pondasi eksisting, untuk hasil perhitungan pondasi baik pondasi tengah maupun pinggir dapat dilihat pada tabel berikut :

Tabel.4.4. Perhitungan Tegangan Di Dasar Pondasi

\begin{tabular}{|c|c|c|c|c|c|c|c|c|c|c|}
\hline \multicolumn{2}{|c|}{ dimensi pondasi } & \multirow{2}{*}{$\mathrm{Pu}$} & \multirow{2}{*}{$\mathrm{Mu}$} & \multirow{2}{*}{ e } & \multirow{2}{*}{$B \times / 6$} & \multicolumn{2}{|c|}{ tegangan yg terjadi pada tanah dasar } & \multicolumn{2}{|c|}{ untuk angka keamanan (3) } & \multirow{2}{*}{\begin{tabular}{|c|} 
daya dukung tanah \\
qa \\
\end{tabular}} \\
\hline $\mathrm{Bx}$ & By & & & & & qmak & qmin & qmak & qmin & \\
\hline 1 & 2 & 3 & 4 & 5 & 6 & 7 & 8 & 9 & 10 & 11 \\
\hline 2 & 2 & 281.5008 & 5.103692 & 0.01813 & 0.333333 & 296.8118399 & 266.1896865 & 890.4355198 & 798.5690596 & $288.8 \mathrm{kN} / \mathrm{m} 2$ \\
\hline 1.7 & 1.7 & 163.5137 & 0.505572 & 0.003092 & 0.283333 & 165.2981 & 161.7293537 & 495.8942999 & 485.1880612 & $288.8 \mathrm{kN} / \mathrm{m} 2$ \\
\hline
\end{tabular}

Sumber; hasil perhitungan berdasarkan rumus $(2.4 \& 2.5)$

Tabel 4.5. Perhitungan Tegangan Geser Satu Arah

\begin{tabular}{|c|c|c|c|c|c|c|c|c|c|c|}
\hline \multicolumn{2}{|c|}{ dimensi pondasi } & \multirow{2}{*}{ Pu } & \multirow{2}{*}{$\mathrm{Mu}$} & \multirow{2}{*}{$a$} & \multirow{2}{*}{$d$} & \multicolumn{2}{|c|}{ egangan yg terjadi pada tanah dasar } & \multicolumn{3}{|c|}{ tegangan geser satu arah } \\
\hline Bx & By & & & & & qmak & qmin & Vu & Vc & $\phi V_{c} \quad \phi V_{c} \geq V_{u}$ \\
\hline 1 & 2 & 3 & 4 & 5 & 6 & 7 & 8 & 9 & 10 & 12 \\
\hline 2 & 2 & 281.5008 & 5.103692 & 1.291 & 0.309 & 296.8118399 & 266.1896865 & 726.8349707 & 897.954 & \begin{tabular}{|l|l}
538.7724 & NNo \\
\end{tabular} \\
\hline 1.7 & 1.7 & 163.5137 & 0.505572 & 0.991 & 0.309 & 165.2981 & 161.7293537 & 278.477709 & 897.954 & 538.7724 OK \\
\hline
\end{tabular}

Sumber; hasil perhitungan berdasarkan rumus $(2.7 \& 2.8)$

Tabel.4.6. Perhitungan Tegangan Geser Pons

\begin{tabular}{|c|c|c|c|c|c|c|c|c|c|c|c|c|c|c|}
\hline \multicolumn{2}{|c|}{ dimensi pondasi } & \multirow{2}{*}{$\mathrm{Pu}$} & \multirow{2}{*}{$\mathrm{Mu}$} & \multirow{2}{*}{$b(\mathrm{~m})$} & \multirow{2}{*}{$h(m)$} & \multirow{2}{*}{$d(m)$} & \multicolumn{2}{|c|}{ tegangan di dasar pondasi } & \multirow{2}{*}{ bo $(m)$} & \multirow{2}{*}{$\operatorname{Bc}(m)$} & \multicolumn{3}{|c|}{ tegangan geser satu arah } & kontrol \\
\hline$B x$ & $\mathrm{By}$ & & & & & & gmak & qmin & & & $V u$ & Vc & $\phi V c$ & $\phi V c \geq V u$ \\
\hline 1 & 2 & 3 & 4 & 5 & 6 & 7 & 8 & 9 & 10 & 11 & 12 & 13 & 14 & 15 \\
\hline 2 & 2 & 281.50 & 5.10 & 0.4 & 0.4 & 0.309 & 296.812 & 266.190 & 2.127 & 1 & 984.50 & 1718.95 & 1031.37 & OK \\
\hline 1.7 & 1.7 & 163.51 & 0.51 & 0.4 & 0.4 & 0.309 & 165.298 & 161.729 & 2.127 & 1 & 320.82 & 1718.95 & 1031.37 & OK \\
\hline
\end{tabular}

Sumber; hasil perhitungan berdasarkan rumus(2.8)

Berdasarkan hasil perhitungan, pondasi eksisting gedung Rektorat AKPER untuk pondasi tengah memiliki dimensi 2,0 x 2,0 meter,untuk kontrol geser satu arahnya tidak memenuhi standar keamanan karena gaya geser lebih besar dari kapasitas penampang beton. Untuk pondasi pinggir menggunakan dimensi $1,7 \mathrm{x}$ 1,7 meter. Kontrol geser satu arah maupun dua arah memenuhi standar keamanan karena nilai tegangan yang dijinkan lebih besar dari tegangan 
ultimitnya. Akan tetapi untuk tegangan ijin pada tanah dasar pondasi cukup besar sehingga dimensi pondasi tersebut tersebut masih memungkinkan untuk diperkecil.

\section{2). Pondasi rencana (pondasi tengah)}

Untuk perhitungan pondasi dapat dilihat pada tabel berikut :

Tabel 4.7. Perhitungan Tegangan Di Dasar Pondasi

\begin{tabular}{|c|c|c|c|c|c|c|c|c|c|c|}
\hline \multicolumn{2}{|c|}{ dimensi pondasi } & \multirow{2}{*}{$\mathrm{Pu}$} & \multirow{2}{*}{$\mathrm{Mu}$} & \multirow{2}{*}{ e } & \multirow{2}{*}{$B \times / 6$} & \multicolumn{2}{|c|}{ tegangan yg terjadi pada tanah dasar } & \multicolumn{3}{|c|}{ untuk angka keamanan (3) daya dukung tanah } \\
\hline$B x$ & By & & & & & qmak & gmin & qmak & qmin & qa \\
\hline 1 & 2 & 3 & 4 & 5 & 6 & 7 & 8 & 9 & 10 & 11 \\
\hline 1.2 & 1.2 & 281.5008 & 5.103692 & 0.01813 & 0.2 & 213.2077947 & 177.7654875 & 639.6233842 & 533.2964626 & $288.8 \mathrm{kN} / \mathrm{m} 2$ \\
\hline 1.4 & 1.4 & 281.5008 & 5.103692 & 0.01813 & 0.233333 & 154.7825153 & 132.4631615 & 464.3475458 & 397.3894845 & $288.8 \mathrm{kN} / \mathrm{m} 3$ \\
\hline 1.5 & 1.5 & 281.5008 & 5.103692 & 0.01813 & 0.25 & 134.184681 & 116.0382197 & 402.5540429 & 348.1146591 & $288.8 \mathrm{kN} / \mathrm{m} 4$ \\
\hline 1.6 & 1.6 & 281.5008 & 5.103692 & 0.01813 & 0.266667 & 117.4373473 & 102.485124 & 352.3120419 & 307.4553719 & $288.8 \mathrm{kN} / \mathrm{m5}$ \\
\hline 1.7 & 1.7 & 281.5008 & 5.103692 & 0.01813 & 0.283333 & 103.6379912 & 91.17222554 & 310.9139737 & 273.5166766 & $288.8 \mathrm{kN} / \mathrm{m} 6$ \\
\hline 1.8 & 1.8 & 281.5008 & 5.103692 & 0.01813 & 0.3 & 92.13366379 & 81.63223944 & 276.4009914 & 244.8967183 & $288.8 \mathrm{kN} / \mathrm{m} 7$ \\
\hline 1.9 & 1.9 & 281.5008 & 5.103692 & 0.01813 & 0.316667 & 82.42257232 & 73.51352919 & 247.327717 & 220.5405876 & $288.8 \mathrm{kN} / \mathrm{m} 8$ \\
\hline 2 & 2 & 281.5008 & 5.103692 & 0.01813 & 0.333333 & 74.20255998 & 66.54742163 & 222.60888 & 199.6422649 & $288.8 \mathrm{kN} / \mathrm{mg}$ \\
\hline
\end{tabular}

sumber : Hasil perhitungan

Tabel 4.8. Perhitungan Tegangan Satu Arah Pada Portal $2 X$

\begin{tabular}{|c|c|c|c|c|c|c|c|c|c|c|c|}
\hline \multicolumn{2}{|c|}{ dimensi pondasi } & \multirow{2}{*}{$\mathrm{Pu}$} & \multirow{2}{*}{$\mathrm{Mu}$} & \multirow{2}{*}{$a$} & \multirow{2}{*}{$d$} & \multicolumn{2}{|c|}{ tegangan yg terjadi pada tanah dasar } & \multicolumn{3}{|c|}{ tegangan geser satu arah } & \multirow{2}{*}{$\begin{array}{l}\text { kontrol } \\
\phi V_{c} \geq V_{u}\end{array}$} \\
\hline $\mathrm{Bx}$ & By & & & & & qmak & qmin & $\mathrm{Vu}$ & Vc & $\phi V c$ & \\
\hline 1 & 2 & 3 & 4 & 5 & 6 & 7 & 8 & 9 & 10 & 11 & 12 \\
\hline 1.2 & 1.2 & 281.5008 & 5.103692 & 0.491 & 0.309 & 213.2077947 & 177.7654875 & 115.180729 & 897.954 & 371.74911 & OK \\
\hline 1.4 & 1.4 & 281.5008 & 5.103692 & 0.691 & 0.309 & 154.7825153 & 132.4631615 & 138.9407339 & 897.954 & 269.87879 & OK \\
\hline 1.5 & 1.5 & 281.5008 & 5.103692 & 0.791 & 0.309 & 134.184681 & 116.0382197 & 148.4447358 & 897.954 & 233.96441 & OK \\
\hline 1.6 & 1.6 & 281.5008 & 5.103692 & 0.891 & 0.309 & 117.4373473 & 102.485124 & 156.7607375 & 897.954 & 204.76376 & OK \\
\hline 1.7 & 1.7 & 281.5008 & 5.103692 & 0.991 & 0.309 & 103.6379912 & 91.17222554 & 164.0983861 & 897.954 & 180.7032 & $\mathrm{OK}$ \\
\hline 1.8 & 1.8 & 281.5008 & 5.103692 & 1.091 & 0.309 & 92.13366379 & 81.63223944 & \begin{tabular}{|l|}
170.6207404 \\
\end{tabular} & 897.954 & 160.64426 & NO \\
\hline 1.9 & 1.9 & 281.5008 & 5.103692 & 1.191 & 0.309 & 82.44257232 & 73.51352919 & 176.4565311 & 897.954 & 143.74687 & NO \\
\hline 2 & 2 & 281.5008 & 5.103692 & 1.291 & 0.309 & 74.20295998 & 66.54742163 & 181.7087427 & 897.954 & 129.38028 & NO \\
\hline
\end{tabular}

Sumber; Hasil perhitungan

Tabel. 4.9. Perhitungan Tegangan Dua Arah (pons)

\begin{tabular}{|c|c|c|c|c|c|c|c|c|c|c|c|c|c|c|}
\hline \multicolumn{2}{|c|}{ dimensi pondasi } & \multirow{2}{*}{$\mathrm{Pu}$} & \multirow{2}{*}{ Mu } & \multirow{2}{*}{$b(m)$} & \multirow{2}{*}{$h(m)$} & \multirow{2}{*}{$d(m)$} & \multicolumn{2}{|c|}{ tegangan yg terjadi pada tanah dasar } & \multirow{2}{*}{ bo $(m)$} & \multirow{2}{*}{$\operatorname{Bc}(\mathrm{m})$} & \multicolumn{3}{|c|}{ tegangan geser satu arah } & \multirow{2}{*}{\begin{tabular}{|l|} 
kontrol \\
$\phi V c \geq V_{u}$
\end{tabular}} \\
\hline $\mathrm{Bx}$ & By & & & & & & qmak & qmin & & & $\mathrm{Vu}$ & $V_{c}$ & $\phi V c$ & \\
\hline 1 & $L$ & 3 & 4 & 5 & 6 & 7 & 0 & $\mathrm{~J}$ & 10 & 11 & 12 & 13 & 14 & 15 \\
\hline 1.2 & 1.2 & 281.5008 & 5.103692 & 0.4 & 0.4 & 0.309 & 213.2077947 & 177.7654875 & 2.127 & 1 & 145.0283619 & 1718.953 & 1031.372 & OK \\
\hline 1.4 & 1.4 & 281.5008 & 5.103692 & 0.4 & 0.4 & 0.309 & 154.7825153 & 132.4631615 & 2.127 & 1 & 157.8432082 & 1718.953 & 1031.372 & OK \\
\hline 1.5 & 1.5 & 281.5008 & 5.103692 & 0.4 & 0.4 & 0.309 & 134.184681 & 116.0382197 & 2.127 & 1 & 166.9532617 & 1718.953 & 1031.372 & OK \\
\hline 1.6 & 1.6 & 281.5008 & 5.103692 & 0.4 & 0.4 & 0.309 & 117.4373473 & 2.485124 & 2.127 & 1 & 177.97991 & 1718.953 & 1031.372 & OK \\
\hline 1.7 & 1.7 & 281.5008 & 5.103692 & 0.4 & 0.4 & 0.309 & 103.6379912 & 91.17222554 & 2.127 & 1 & 191.1101765 & 1718.953 & 1031.372 & OK \\
\hline 1.8 & 1.8 & 281.5008 & 5.103692 & 0.4 & 0.4 & 0.309 & 92.13366379 & 81.63223944 & 2.127 & 1 & 206.604974 & 1718.953 & 1031.372 & OK \\
\hline 1.9 & 1.9 & 281.5008 & 5.103692 & 0.4 & 0.4 & 0.309 & 82.44257232 & 73.51352919 & 2.127 & 1 & 224.8020916 & 1718.953 & 1031.372 & OK \\
\hline 2 & 2 & 281.5008 & 5.103692 & 0.4 & 0.4 & 0.309 & 74.20295998 & 66.54742163 & 2.127 & 1 & 246.1244919 & 1718.953 & 1031.372 & OK \\
\hline
\end{tabular}

Sumber : Hasil perhitungan 


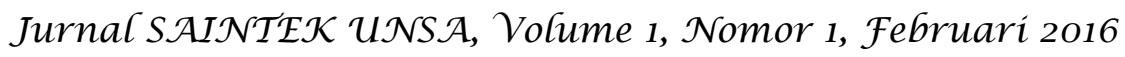

Tabel 4.10. Perhitungan Rencana Tulangan Pondasi Tegah (portal 2X)

\begin{tabular}{|c|c|c|c|c|c|c|c|c|c|c|c|c|c|c|}
\hline \multicolumn{2}{|c|}{ dimensi pondasi } & \multirow{2}{*}{$\mathrm{Pu}$} & \multirow{2}{*}{$\mathrm{Mu}$} & \multirow{2}{*}{ pmin } & \multirow{2}{*}{$\rho$} & \multirow{2}{*}{$\rho$ mak } & \multirow{2}{*}{$d$} & \multirow{2}{*}{$\sigma x$} & \multicolumn{2}{|c|}{ tegangan pd t.dasar } & \multirow{2}{*}{$x$} & \multirow{2}{*}{ As perlu } & \multirow{2}{*}{\begin{tabular}{|l} 
banyak \\
tulangan
\end{tabular}} & \multirow{2}{*}{\begin{tabular}{|c|} 
jarak \\
tulangan \\
\end{tabular}} \\
\hline$B x$ & By & & & & & & & & qmak & qmin & & & & \\
\hline 1 & 2 & 3 & 4 & 5 & 6 & 7 & 8 & 9 & 10 & 11 & 12 & 13 & 14 & 15 \\
\hline 1.2 & 1.2 & 281.5008 & 5.103692 & 0.00359 & 0.021333 & 0.015999 & 309 & 213.196 & 213.2078 & 177.7655 & 0.4 & 1331.077 & 6.623591 & 181.1706 \\
\hline 1.4 & 1.4 & 281.5008 & 5.103692 & 0.00359 & 0.021333 & 0.015999 & 309 & 154.7745 & 154.7825 & 132.4632 & 0.5 & 1552.923 & 7.727523 & \begin{tabular}{|l|l|}
181.1706 \\
\end{tabular} \\
\hline 1.5 & 1.5 & 281.5008 & 5.103692 & 0.00359 & 0.021333 & 0.015999 & 309 & \begin{tabular}{|l|l|}
134.178 \\
\end{tabular} & 134.1847 & 116.0382 & 0.55 & 1663.846 & 8.279489 & 181.1706 \\
\hline 1.6 & 1.6 & 281.5008 & 5.103692 & 0.00359 & 0.021333 & 0.015999 & 309 & 117.4317 & 1117.4373 & 102.4851 & 0.6 & 1774.769 & 8.831455 & $\mid$\begin{tabular}{|l|l|}
181.1706 \\
\end{tabular} \\
\hline 1.7 & 1.7 & 281.5008 & 5.103692 & 0.00359 & 0.021333 & 0.015999 & 309 & 103.6332 & 103.638 & 91.17223 & 0.65 & 1885.692 & 9.383421 & 181.1706 \\
\hline 1.8 & 1.8 & 281.5008 & 5.103692 & 0.00359 & 0.021333 & 0.015999 & 309 & 92.12958 & 92.13366 & 81.63224 & 0.7 & 1996.615 & 9.935387 & 181.1706 \\
\hline 1.9 & 1.9 & 281.5008 & 5.103692 & 0.00359 & 0.021333 & 0.015999 & 309 & 82.43905 & 82.44257 & 73.51353 & 0.75 & 2107.538 & 10.48735 & 181.1706 \\
\hline 2 & 2 & 281.5008 & 5.103692 & 0.00359 & 0.021333 & 0.015999 & 309 & 74.1999 & 74.20296 & 66.54742 & 0.8 & 2218.462 & 11.03932 & 181.1706 \\
\hline
\end{tabular}

Sumber : Hasil perhitungan.

\section{3). Pondasi rencana (pondasi pinggir)}

Untuk perhitungan pondasi rencana pinggir dapat dilihat pada tabel berikut :

Tabel 4.11. Tegangan Pada Tanah Dasar Untuk Pondasi Portal 1Y

\begin{tabular}{|c|c|c|c|c|c|c|c|c|c|c|}
\hline \multicolumn{2}{|c|}{ dimensi pondasi } & \multirow{2}{*}{$\mathrm{Pu}$} & \multirow{2}{*}{$\mathrm{Mu}$} & \multirow{2}{*}{ e } & \multirow{2}{*}{$B x / 6$} & \multicolumn{2}{|c|}{ tegangan yg terjadi pada tanah dasar } & \multicolumn{3}{|c|}{ untuk angka keamanan (3) daya dukung tanah } \\
\hline$B x$ & By & & & & & qmak & qmin & qmak & qmin & $q a$ \\
\hline 1 & 2 & 3 & 4 & 5 & 6 & 7 & 8 & 9 & 10 & 11 \\
\hline 1.2 & 1.2 & 163.514 & 0.506 & 0.003 & 0.2 & 166.0416 & 160.9859 & 498.1248 & 482.9576 & $1404 \mathrm{kN} / \mathrm{m} 2$ \\
\hline 1.4 & 1.4 & 163.514 & 0.506 & 0.003 & 0.233333 & 165.6805 & 161,3470 & 497.0414 & 484.0410 & $1404 \mathrm{kN} / \mathrm{m} 3$ \\
\hline 1.5 & 1.5 & 163.514 & 0.506 & 0.003 & 0.25 & 165.5360 & 161.4914 & 496.6080 & 484.4743 & $1404 \mathrm{kN} / \mathrm{m} 4$ \\
\hline 1.6 & 1.6 & 163.514 & 0.506 & 0.003 & 0.266667 & 165.4096 & 161.6178 & 496.2289 & 484.8535 & $1404 \mathrm{kN} / \mathrm{m} 5$ \\
\hline 1.7 & 1.7 & 163.514 & 0.506 & 0.003 & 0.283333 & 165.2981 & 161.7294 & 495.8943 & 485.1881 & $1404 \mathrm{kN} / \mathrm{mb}$ \\
\hline 1.8 & 1.8 & 163.514 & 0.506 & 0.003 & 0.3 & 165.1990 & 161.8285 & 495.5969 & 485.4855 & $1404 \mathrm{kN} / \mathrm{m} 7$ \\
\hline 1.9 & 1.9 & 163.514 & 0.506 & 0.003 & 0.316667 & 165.1103 & 161.9172 & 495.3308 & 485.7515 & $1404 \mathrm{kN} / \mathrm{m8}$ \\
\hline 2 & 2 & 163.514 & 0.506 & 0.003 & 0.333333 & 165.0304 & 161.9970 & 495.0913 & 485.9910 & $1404 \mathrm{kN} / \mathrm{mg}$ \\
\hline
\end{tabular}

Sumber : Hasil perhitungan

Tabel.4.12. Tegangan Gesesr Satu Arah Pondasi 1Y

\begin{tabular}{|c|c|c|c|c|c|c|c|c|c|c|c|}
\hline \multicolumn{2}{|c|}{ dimensi pondasi } & \multirow{2}{*}{ Pu } & \multirow{2}{*}{$\mathrm{Mu}$} & \multirow{2}{*}{ a } & \multirow{2}{*}{$d$} & \multicolumn{2}{|c|}{ tegangan yg terjadi pada tanah dasar } & \multicolumn{3}{|c|}{ tegangan geser satu arah } & \multirow{2}{*}{$\begin{array}{l}\text { kontrol } \\
\phi V c \geq V u\end{array}$} \\
\hline$B x$ & By & & & & & qmak & gmin & Vu & $V_{c}$ & $\phi V c$ & \\
\hline 1 & 2 & 3 & 4 & 5 & 6 & 7 & 8 & 9 & 10 & 11 & 12 \\
\hline 1.2 & 1.2 & 163.5137 & 0.505572 & 0.491 & 0.309 & 166.0415888 & 160.9858649 & 96.34228786 & 897.954 & 538.7724 & OK \\
\hline 1.4 & 1.4 & 163.5137 & 0.505572 & 0.691 & 0.309 & 165.6804656 & 161.3469881 & 158.1831794 & 897.954 & 538.7724 & OK \\
\hline 1.5 & 1.5 & 163.5137 & 0.505572 & 0.791 & 0.309 & 165.5360164 & 161.4914373 & 194.0090369 & 897.954 & 538.7724 & OK \\
\hline 1.6 & 1.6 & 163.5137 & 0.505572 & 0.891 & 0.309 & 165.4096233 & 161.6178304 & 233.105169 & 897.954 & 538.7724 & OK \\
\hline 1.7 & 1.7 & 163.5137 & 0.505572 & 0.991 & 0.309 & 165.2981 & 161.7293537 & 275.4715756 & 897.954 & 538.7724 & OK \\
\hline 1.8 & 1.8 & 163.5137 & 0.505572 & 1.091 & 0.309 & 165.1989681 & 161.8284856 & 321.1082568 & 897.954 & 538.7724 & OK \\
\hline 1.9 & 1.9 & 163.5137 & 0.505572 & 1.191 & 0.309 & 165.1102712 & 161.9171825 & 370.0152125 & 897.954 & 538.7724 & OK \\
\hline 2 & 2 & 163.5137 & 0.505572 & 1.291 & 0.309 & 165.030444 & 161.9970097 & 422.1924427 & 897.954 & 538.7724 & OK \\
\hline
\end{tabular}

Sumber : Hasil perhitungan 
Tabel 4.13. Tegangan Gesesr Dua Arah (pons) pondasi $1 Y$

\begin{tabular}{|c|c|c|c|c|c|c|c|c|c|c|c|c|c|c|}
\hline \multicolumn{2}{|c|}{ dimensi pondasi } & \multirow{2}{*}{ Pu } & \multirow{2}{*}{$\mathrm{Mu}$} & \multirow{2}{*}{$b(m)$} & \multirow{2}{*}{$h(m)$} & \multirow{2}{*}{$d(m)$} & \multicolumn{2}{|c|}{ tegangan yg terjadi pada tanah dasar } & \multirow{2}{*}{$b_{0}(m)$} & \multirow{2}{*}{$\operatorname{Bc}(\mathrm{m})$} & \multicolumn{3}{|c|}{ tegangan geser satu arah } & \multirow{2}{*}{$\frac{\text { kontrol }}{\phi V} \geq V_{u}$} \\
\hline$B x$ & By & & & & & & qmak & qmin & & & $\mathrm{Vu}$ & $V_{c}$ & $\phi \vee c$ & \\
\hline 1 & 2 & 3 & 4 & 5 & 6 & 7 & 8 & 9 & 10 & 11 & 12 & 13 & 14 & 15 \\
\hline 1.2 & 1.2 & 163.5137 & 0.505572 & 0.4 & 0.4 & 0.309 & 166.0415888 & 160.9858649 & 2.127 & 1 & 121.3081764 & 1718.953 & 1031.372 & OK \\
\hline 1.4 & 1.4 & 163.5137 & 0.505572 & 0.4 & 0.4 & 0.309 & 165.6804656 & 161.3469881 & 2.127 & 1 & 179.7035313 & 1718.953 & 1031.372 & OK \\
\hline 1.5 & 1.5 & 163.5137 & 0.505572 & 0.4 & 0.4 & 0.309 & 165.5360164 & 161.4914373 & 2.127 & 1 & 218.1986538 & 1718.953 & 1031.372 & OK \\
\hline 1.6 & 1.6 & 163.5137 & 0.505572 & 0.4 & 0.4 & 0.309 & 165.4096233 & 161.6178304 & 2.127 & 1 & 264.6583427 & 1718.953 & 1031.372 & OK \\
\hline 1.7 & 1.7 & 163.5137 & 0.505572 & 0.4 & 0.4 & 0.309 & 165.2981 & 161.7293537 & 2.127 & 1 & 320.8162048 & 1718.953 & 1031.372 & OK \\
\hline 1.8 & 1.8 & 163.5137 & 0.505572 & 0.4 & 0.4 & 0.309 & 165.1989681 & 161.8284856 & 2.127 & 1 & 388.8305894 & 1718.953 & 1031.372 & OK \\
\hline 1.9 & 1.9 & 163.5137 & 0.505572 & 0.4 & 0.4 & 0.309 & 165.1102712 & 161.9171825 & 2.127 & 1 & \begin{tabular}{|l|}
471.3919807 \\
\end{tabular} & 1718.953 & 1031.372 & OK \\
\hline 2 & 2 & 163.5137 & 0.505572 & 0.4 & 0.4 & 0.309 & 165.030444 & 161.9970097 & 2.127 & 1 & 571.8596637 & 1718.953 & 1031.372 & OK \\
\hline
\end{tabular}

Sumber ; Hasil perhitungan

Tabel 4.14. Rencana Tulangan Pondasi pinggir (portal 1Y)

\begin{tabular}{|c|c|c|c|c|c|c|c|c|c|c|c|c|c|c|}
\hline \multicolumn{2}{|c|}{ dimensi pondasi } & \multirow{2}{*}{$\mathrm{Pu}$} & \multirow{2}{*}{$\mathrm{Mu}$} & \multirow{2}{*}{$\rho \min$} & \multirow{2}{*}{$\rho$ mak } & \multirow{2}{*}{$\rho$} & \multirow{2}{*}{$d$} & \multirow{2}{*}{$\sigma x$} & \multicolumn{2}{|c|}{ tegangan pd t.dasar } & \multirow{2}{*}{$x$} & \multirow{2}{*}{ As perlu } & \multirow{2}{*}{\begin{tabular}{|c|} 
banyak \\
tulangan \\
\end{tabular}} & \multirow{2}{*}{\begin{tabular}{|c} 
jarak \\
tulangan
\end{tabular}} \\
\hline $\mathrm{Bx}$ & By & & & & & & & & qmak & qmin & & & & \\
\hline 1 & 2 & 3 & 4 & 5 & 6 & 7 & 8 & 9 & 10 & 11 & 12 & 13 & 14 & 15 \\
\hline 1.2 & 1.2 & 163.5137 & 0.505572 & 0.00359 & 0.015999 & 0.021333 & 309 & 166.0399 & 166.0416 & 160.9859 & 0.4 & 1331.077 & 6.623591 & 181.1706 \\
\hline 1.4 & 1.4 & 163.5137 & 0.505572 & 0.00359 & 0.015999 & 0.021333 & 309 & 165.6789 & 165.6805 & 161.347 & 0.5 & 1552.923 & 7.727523 & 181.1706 \\
\hline 1.5 & 1.5 & 163.5137 & 0.505572 & 0.00359 & 0.015999 & 0.021333 & 309 & 165.5345 & 165.536 & 161.4914 & 0.55 & 1663.846 & 8.279489 & 181.1706 \\
\hline 1.6 & 1.6 & 163.5137 & 0.505572 & 0.00359 & 0.015999 & 0.021333 & 309 & 165.4082 & 165.4096 & 161.6178 & 0.6 & 1774.769 & 8.831455 & 181.1706 \\
\hline 1.7 & 1.7 & 163.5137 & 0.505572 & 0.00359 & 0.015999 & 0.021333 & 309 & 165.2967 & 165.2981 & 161.7294 & 0.65 & 1885.692 & 9.383421 & 181.1706 \\
\hline 1.8 & 1.8 & 163.5137 & 0.505572 & 0.00359 & 0.015999 & 0.021333 & 309 & 165.1977 & 165.199 & 161.8285 & 0.7 & 1996.615 & 9.935387 & 181.1706 \\
\hline 1.9 & 1.9 & 163.5137 & 0.505572 & 0.00359 & 0.015999 & 0.021333 & 309 & 165.109 & 165.1103 & 161.9172 & 0.75 & 2107.538 & 10.48735 & 181.1706 \\
\hline 2 & 2 & 163.5137 & 0.505572 & 0.00359 & 0.015999 & 0.021333 & 309 & 165.0292 & 165.0304 & 161.997 & 0.8 & 2218.462 & 11.03932 & 181.1706 \\
\hline
\end{tabular}

Sumber : Hasil perhitungan

Dari hasil perhitungan, dipilihlah pondasi dengan dimensi 1,7 x 1,7 meter untuk pondasi tengah $(2 X)$ dan pondasi dengan dimensi $1,5 \times 1,5$ meter untuk pondasi pinggir (1Y), dengan dimensi eksisting pondasi tengah $2 \times 2$ meter, pondasi pinggir $1,7 \times 1,7$ meter. Dengan alasan untuk dimensi pondasi tengah $2 \times$ 2 meter tidak kuat menahan gaya geser dua arah sehingga dimensinya perlu diperkecil agar sesuai dengan tebal pondasi atau dipasang tulangan geser pada pondasi tersebut. Untuk pondasi pinggir dimensi eksisting dan dimensi rencana sama-sama kuat menahan gaya geser satu arah maupun dua arah, jadi kedua dimensi tersebut bisa digunakan.

\section{Perbandingan pondasi eksisting dan pondasi rencana.}

Untuk menentukan jenis pondasi yang lebih efektif dan efisien digunakan bukan hanya melihat dari faktor kekuatan struktur menahan beban-beban yang 


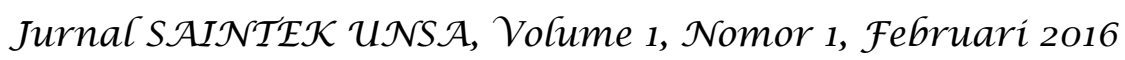

bekerja,tetapi juga perlu di tinjau dari segi biaya. Perbandingan pondasi eksisting dan pondasi rencana dapat dilihat pada tabel berikut :

Tabel.4.15. Perbandingan Pondasi Eksisting Dengan Pondasi Rencana.

\begin{tabular}{|c|c|c|c|c|c|}
\hline & & \multicolumn{2}{|c|}{ pondasi eksisting } & \multicolumn{2}{|c|}{ pondasi rencana } \\
\hline & & pondasi tengah (2X) & pondasi pinggir (1Y) & pondasi tengah $(2 \mathrm{X})$ & pondasi pinggir (1Y) \\
\hline dimensi pondasi & & $2,0 \times 2,0$ meter & $1,7 \times 1,7$ meter & $1,7 \times 1,7$ meter & $1,5 \times 1,5$ meter \\
\hline \multirow{2}{*}{$\begin{array}{l}\text { tegangan yg terjadi di } \\
\text { dasar tanah }\left(\mathrm{kg} / \mathrm{m}^{2}\right)\end{array}$} & o mak & 138,2039172 & 99,66891833 & 299,5137947 & 165,5360164 \\
\hline & $\sigma \min$ & 130,5464645 & 96,10017209 & 263,4877318 & 161,4914373 \\
\hline \multirow{2}{*}{$\begin{array}{l}\text { tegangan geser satu } \\
\text { arah (kN) }\end{array}$} & Vu & 134,7932135 & 57,57058326 & 474,2443358 & 334,0006556 \\
\hline & $\phi V c$ & 538,7724 & 538,7724 & 522,2322524 & 526,4199219 \\
\hline \multirow{2}{*}{$\begin{array}{c}\text { tegangan geser dua } \\
\operatorname{arah}(\mathrm{kN})\end{array}$} & Vu & 469,9529079 & 192,0508382 & 552,3084102 & 375,6448389 \\
\hline & $\phi V c$ & 859,4766711 & 859,4766711 & 1031,372005 & 1031,372005 \\
\hline $\mathrm{RAB}(\mathrm{Rp})$ & & $4.692 .506,39$ & $3.419 .841,77$ & $4.109 .498,02$ & 3.199.436,17 \\
\hline
\end{tabular}

Sumber; hasil perhitungan

\section{KESIMPULAN DAN SARAN}

\subsection{KESIMPULAN}

Berdasarkan hasil perhitungan dan analisa, dapat ditarik beberapa kesimpulan yaitu :

1). Secara teoritis dari data sondir dapat diketahui bahwa penggunaan pondasi tiang pancang pada gedung Rektorat AKPER Sumbawa kurang efisien apabila digunakan, karena pada kedalaman 2 meter daya dukungnya sudah sangat besar, sehingga pondasi tiang pancang tidak perlu dijadikan alternatif pondasi pilihan untuk gedung Rektorat AKPER Sumbawa.

2). Perhitungan daya dukung dengan menggunakan metode mayerhorf menghasilkan tegangan ijin sebesar qa=288,8 kN/m.

3). Dari hasil perhitungan struktur dengan metode cross didapatkan nilai beban terbesar ada pada portal $2 \mathrm{X}$ dengan $\mathrm{Pu}=281,5008 \mathrm{kN}$, dan momen ultimit $\mathrm{Mu}=5,1036 \mathrm{kNm}$, nilai ini yang dijadikan dasar dalam menentukan dimensi pondasi tengah.

4). untuk pondasi pinggir beban terbesar ada pada portal $1 Y$ dengan nilai $\mathrm{Pu}=163,514 \mathrm{kN}$ dan $\mathrm{Mu}=0,5056 \mathrm{kNm}$, nilai ini yang dijadikan dasar dalam menentukan dimensi pondasi pinggir. 


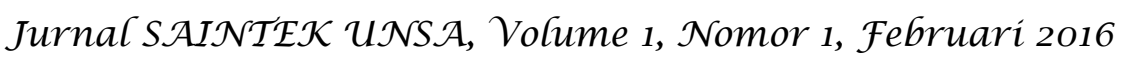

5). Dari hasil analisa pondasi baik pondasi eksisting maupun pondasi rencana sama-sama mampu menahan tegangan dan gaya geser baik satu arah maupun dua arah akan tetapi dari hasil perhitungan RAB didapatkan perbedaan biaya pondasi rencana dengan pondasi eksisting, untuk pondasi tengah pada pondasi rencana harganya Rp.4.109.498,02/unit dan pondasi tengah eksisting harganya Rp.4.692.506,39/unit pondasi dan untuk pondasi pinggir rencana harganya Rp.3.199.436,17-/unit pondasi dan pondasi pinggir eksisting harganya Rp.3.419.841,77/unit pondasi.

\subsection{SARAN}

Untuk peneliti selanjutnya agar menghitung beban gempa pada perhitungan struktur bangunannya, karena pengaruh besarnya beban gempa akan sangat mempengaruhi besarnya beban ultimit dan momen ultimit yang nantinya akan digunakan untuk perhitungan dimensi pondasi.

\section{DAFTAR PUSTAKA}

Badan Standarisasi Nasional. (2002). SNI 03-1729-2002 : Tata Cara Perencanaan Struktur Baja Untuk Bangunan Gedung. Badan Standarisasi Nasional.

Badan Standarisasi Nasional. (2012). SNI 1726:2012 : Tata cara perencanaan ketahanan gempa untuk struktur bangunan gedung dan non gedung. Badan Standarisasi Nasional.

Departemen Pekerjaan Umum, 1987. SKBI 1.3.53.1987 Pedoman Perencanaan Pembebanan untuk Rumah dan Gedung, Yayasan Badan Penerbit PU, Jakarta.

Frick, Heinz. 1979. "Statika dan Kegunaannya”, Mekanika Teknik 2 Jilid II. Kanisius, Yogyakarta.

Indarto, Himawan dkk. 2013. Aplikasi SNI Gempa 1726:2012 for Dummies . Semarang : Fakultas Teknik Universitas Negeri Semarang.

Pramono, Handi dkk. 2007. 12 Tutorial Latihan Desain Konstruksi Dengan SAP2000 Versi 9. Andi, Yogyakarta.

Pramono, Handi dkk. 2007. Desain Konstruksi Plat Dan Rangka Beton Bertulang Dengan SAP2000 Versi 9. Andi, Yogyakarta.

Purnama, A, 2011. Studi Kelayakan Pembangunan Pembangkit Listrik Tenaga Mikrohidro Studi Kasus: PLTMH Minggir pada saluran irigasi Minggir di Padukuhan Klagaran Desa Sendangrejo Kecamatan Minggir Kabupaten 


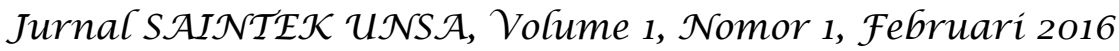

Sleman, Jurnal Unsa Progress. Vol.10, No.15, Oktober, Universitas Samawa, Sumbawa Besar.

Schodek, Daniel L, Struktur (terjemahan). Erlangga, Jakarta.

Soetomo, HM, 1981. Perhitungan Portal Bertingkat Dengan Cara Takabeya Jilid I. Jakarta.

Soetomo, HM, 1981. Perhitungan Portal Bertingkat Dengan Cara Takabeya Jilid II. Jakarta.

Y, hadi CE.1986. Perhitungan Konstruksi Baja Lengkap. Yustadi.Jakarta. 